\title{
Enhanced Visible-Light-Driven Photocatalytic Activity of ZnAl Layered Double Hydroxide by Incorporation of $\mathrm{Co}^{2+}$
}

\author{
Deyang Li, Lihui Fan, Min Qi, Yanming Shen*, Dongbin Liu, Shifeng Li
}

School of Chemical Engineering, Shenyang University of Chemical Technology, China

Received: $3^{\text {rd }}$ February 2018; Revised: $8^{\text {th }}$ July 2018; Accepted: $13^{\text {rd }}$ July 2018; Available online: 14 $4^{\text {th }}$ November 2018; Published regularly: December 2018

\begin{abstract}
Co-doped $\mathrm{ZnAl}$ layered double hydroxides (LDH) were papered by coprecipitation. The prepared samples were characterized by multiple techniques including X-ray Diffraction (XRD), Brunauer-Emmett-Teller (BET) surface area, Scanning Electronic Microscopy (SEM), Transmission Electron Microscopy (TEM), X-ray Photoelectron Spectroscopy (XPS) and UV-Vis Diffuse-Reflectance Spectroscopy (UV-Vis DRS). The incorporation of $\mathrm{Co}^{2+}$ into the $\mathrm{ZnAl} \mathrm{LDH}$ sheets as $\mathrm{CrO}_{6}$ octahedron forms a new energy level which contributes for the excitation of electrons under visible light. The doped $\mathrm{Co}^{2+}$ at a reasonable content also serves as photo-generated charges separator and improves the visible light photocatalytic activity of $\mathrm{ZnAl} \mathrm{LDH.} \mathrm{A} \mathrm{degradation} \mathrm{mechanism} \mathrm{based} \mathrm{on} \mathrm{the} \mathrm{hydroxyl} \mathrm{radical} \mathrm{as} \mathrm{the} \mathrm{ac-}$ tive species was proposed. Copyright (C) 2018 BCREC Group. All rights reserved
\end{abstract}

Keywords: Layered Double Hydroxides; Cobalt-doping; RhB Degradation; Visible Light

How to Cite: Li, D., Fan, L., Qi, M., Shen, Y., Liu, D., Li, S. (2018). Enhanced Visible-Light-Driven Photocatalytic Activity of $\mathrm{ZnAl}$ Layered Double Hydroxide by Incorporation of $\mathrm{Co}^{2+}$. Bulletin of Chemical Reaction Engineering \& Catalysis, 13 (3): 502-511 (doi:10.9767/bcrec.13.3.2168.502-511)

Permalink/DOI: https://doi.org/10.9767/bcrec.13.3.2168.502-511

\section{Introduction}

Layered double hydroxide $(\mathrm{LDH})$ is a group of inorganic compounds composed of positively charged layers with anions distributed between the layers [1]. The chemical composition of LDH can be expressed as the general formula $\left[\mathrm{M}_{1 \cdot x^{2+}} \mathrm{M}_{x}{ }^{3+}(\mathrm{OH})_{2}\right]^{\mathrm{x}+}\left[\mathrm{A}_{x / n^{\mathrm{n}}}\right]_{\mathrm{x} / \mathrm{m}} \cdot \mathrm{H}_{2} \mathrm{O}$. The divalent cations $\mathrm{M}^{2+}$, such as: $\mathrm{Ca}^{2+}, \mathrm{Mg}^{2+}, \mathrm{Zn}^{2+}, \mathrm{Fe}^{2+}$, $\mathrm{Co}^{2+}, \mathrm{Ni}^{2+}, \mathrm{Cu}^{2+}$, etc., are partially substituted by trivalent ones $\mathrm{M}^{3+}\left(\mathrm{Al}^{3+}, \mathrm{Fe}^{3+}, \mathrm{Co}^{3+}, \mathrm{Mn}^{3+}\right.$, $\mathrm{Ni}^{3+}, \mathrm{Cr}^{3+}$, etc.), leading to the generation of a positively charged layer. As a consequence, anions can be intercalated into the interlayer space of the LDH to maintain charge neutrality $[2,3]$.

* Corresponding Author.

E-mail: sym6821@sina.com.cn (Y. Shen)

Telp: +86-024-89383529, Fax: +86-024-89383730
The quantities of the layer metal cations and the anions between the layers are adjustable to bring changes to the layer charge density and other chemical properties, therefore, it could generate useful novel catalytic properties for the LDHs materials, such as catalysis, electrocatalysis, energy storage, photocatalysis, adsorption, and films/coatings for protection $[4,5]$. Recently LDHs has been used as an efficient and effective photocatalyst on the organic pollutant degradation reaction, as they are nontoxic, cheap and easily to prepare [6, 7]. The pioneer work may be reported by Silva and coauthors [8]. They prepared $\mathrm{ZnTi}, \mathrm{ZnCe}$ and $\mathrm{ZnCr} \mathrm{LDH}$ s photocatalysts for generation of oxygen through photocatalytic water splitting under visible light irradiation. These photocatalysts showed good visible light oxygen generation activities. After 
that numbers of $\mathrm{LDH}$ materials, like $\mathrm{MgAl}$ $\mathrm{LDH}$ [9], $\mathrm{CuFe} \mathrm{LDH}$ [10], ZnM LDH $(\mathrm{M}=\mathrm{Al}$, $\mathrm{Fe}, \mathrm{Ti}$, and $\mathrm{Fe} / \mathrm{Ti}$ ) [11], $\mathrm{ZnCr} \mathrm{LDH}$ [12], $\mathrm{CoFe}$ $\mathrm{LDH}$ [7] LDH, $\mathrm{MnCr} \mathrm{LDH}$ [6], etc., were developed as photocatalysts for degradation of organic contaminants. Among these photocatalysts, Zn-based LDHs photocatalysts found an increasing interest in the past few years [1115]. Most of the reported photoactive $\mathrm{Zn}$-based $\mathrm{LDH}$ materials have a $\mathrm{Zn} / \mathrm{Al}$ nominal molar ratio close to 2 , however, the bigger band gap energy limits the $\mathrm{ZnAl} \mathrm{LDH}$ photocatalyst to be driven by UV light.

Generally, photocatalysts acquire high energy by absorbing suitable wavelength of photons. This high energy is used to shift the electrons from valence band (VB) to the conduction band $(\mathrm{CB})$ which causes a redox reaction. This kind of shifting of electrons can be made more feasible by the following three methods: (i) by doping or coating the native compounds with suitable metal compounds. (ii) by changing their morphologies with the change in chemical compositions. (iii) by altering the synthesis methodologies [16]. It have been reported that modification of $\mathrm{ZnAl} \mathrm{LDH}$ catalysts by doping metal ions or oxides can improve their photocatalytic activities under visible light [1721]. Morales-Mendoza et al. $[18,19]$ studied Mndoped $\mathrm{Zn} / \mathrm{Al} \mathrm{LDH}$ with $\mathrm{Mn}$ 0.5-3.0 \% mol respect to $\mathrm{Zn}$ content with improved photocatalytic degradation of 4-chlorophenol (4Clphenol). They suggested the proposed mechanism is that $\mathrm{Mn}$ enhances the charge separation acting as electron $\mathrm{e}^{-}\left(\mathrm{Mn}^{3+} ; \mathrm{Mn}^{4+}\right)$ or hole $\mathrm{h}^{+}\left(\mathrm{Mn}^{2+}\right.$; $\mathrm{Mn}^{3+}$ ) traps according to its oxidation state. The results reported by Parida et al. [22] showed that the substitution of $\mathrm{Fe}^{3+}$ into $\mathrm{Mg} / \mathrm{Al}-\mathrm{CO}_{3} \mathrm{LDH}$ can make it visible light active in water decomposition. The presence of iron favours the migration of photoproduced electrons to the conduction band and $\mathrm{Fe}^{3+}$ ions trap electrons, thus improving the electron hole separation.

We prepared Ni-doped ZnAl LDH and investigated the visible light driven photocatalytic activity for degradation of Rhodamine $\mathrm{B}(\mathrm{RhB})$ [23]. The results showed that the doped $\mathrm{Ni}^{2+}$ served as photo-generated charges separator which promoted the separation of electron and hole. It was reported that Co doping can be used to decorate the electron structure of metal oxides and achieve visible-light absorption [24]. In this present work, we prepared cobalt doped $\mathrm{ZnAl} \mathrm{LDH}$ and investigated its photocatalytic activity under visible light irradiation. The role of $\mathrm{Co}^{2+}$ was discussed and the degradation mechanism under visible light irradiation for $\mathrm{RhB}$ was proposed.

\section{Materials and Methods}

\subsection{Preparation of Co-doped ZnAl LDHs}

All the reagents were of chemical reagent grade and purchased from Sinopharm Chemical Reagent Company, Ltd., China. They were used without further purification. Doubleddistilled water was employed for all experiments. Co-doped $\mathrm{ZnAl} \mathrm{LDHs} \mathrm{were} \mathrm{prepared} \mathrm{by}$ a coprecipitation process at room temperature under air. Aqueous solutions $(250 \mathrm{~mL})$ with the desired amounts of $\mathrm{Zn}\left(\mathrm{NO}_{3}\right)_{2} \cdot 6 \mathrm{H}_{2} \mathrm{O}$, $\mathrm{Co}\left(\mathrm{NO}_{3}\right)_{2} \cdot 6 \mathrm{H}_{2} \mathrm{O}$ and $\mathrm{Al}\left(\mathrm{NO}_{3}\right)_{3} \cdot 9 \mathrm{H}_{2} \mathrm{O}$, the total cation concentration is $1 \mathrm{~mol} / \mathrm{L}$, as precursors, and aqueous solutions with $\mathrm{NaOH}$ and $\mathrm{Na}_{2} \mathrm{CO}_{3}$ $\left(\left[\mathrm{OH}^{-}\right]=2\left(\left[\mathrm{M}^{2+}\right]+\left[\mathrm{M}^{3+}\right]\right),\left[\mathrm{CO}_{3}{ }^{2}\right]=0.5\left[\mathrm{M}^{3+}\right]\right)$, as precipitants, were prepared. The $\mathrm{Co} / \mathrm{Zn} / \mathrm{Al}$ atomic ratios in the precursor solutions were set as $0 / 2 / 1,0.1 / 2 / 1,2 / 2 / 1$, and $4 / 2 / 1$. The precursor and precipitant solutions were added dropwise simultaneously with vigorous stirring into deionized water $(300 \mathrm{~mL})$ in a beaker glass at room temperature, keeping the $\mathrm{pH}$ at approximately 10 by controlling the addition speeds. The resulting mixtures were aged for $24 \mathrm{~h}$ at $65{ }^{\circ} \mathrm{C}$, then filtered and washed with a large amount of water until $\mathrm{pH}$ was around 7 . The resulting products were dried at $80^{\circ} \mathrm{C}$ in an air oven overnight and Co-doped $\mathrm{ZnAl}$ LDHs were obtained. The resulted samples were labeled as Co-0, Co-0.1, Co-1.0, Co-2.0, and Co-4.0 according to the Co ratios in the samples.

\subsection{Characterization}

X-ray diffraction (XRD) patterns were recorded on a Rigaku Dmax 2000 diffractometer with $\mathrm{Cu}-\mathrm{Ka}$ irradiation source, ranging from $5^{\circ}$ to $70^{\circ}$. Scanning electron microscope (SEM) images were taken by JSM-6360LV (JEOL, Japan) at $10.0 \mathrm{kV}$. TEM micrographs were performed on FEI TECNAI-10. X-ray photoelectron spectroscopy (XPS) measurements were performed on a XSAM 800. A $\mathrm{Mg}-\mathrm{K} a$ $\mathrm{X}$-ray source was used at $12 \mathrm{kV}$ and $12 \mathrm{~mA}$. The X-ray photoelectron spectra were referenced to the $\mathrm{C} 1 \mathrm{~s}$ peak $(\mathrm{BE}=284.80 \mathrm{eV})$ resulting from adventitious hydrocarbon (i.e. from the XPS instrument itself) present on the sample surface. UV-vis diffuse reflectance spectra were recorded on a UV-vis spectrophotometer (UV-2550, Shimadzu) equipped with an integrating sphere, and $\mathrm{BaSO}_{4}$ was used as the reference. A V-SORB 2800P specific surface 
and pore size analyzer (Gold APP, China) was used to estimate the specific surface area and pore size of as-prepared samples. The samples were evacuated $3 \mathrm{~h}$ at $523 \mathrm{~K}$, then cooled to 77 $\mathrm{K}$ using liquid $\mathrm{N}_{2}$ at which point $\mathrm{N}_{2}$ adsorption was measured.

\subsection{Evaluation of the Photocatalytic Activity}

The irradiation source was a $300 \mathrm{~W}$ Xe lamp purchased from Hefei Haibilan Scientific Instruments Co,. Ltd., China. Light was passed through a cutoff filter $(\lambda>420 \mathrm{~nm}$ for visiblelight illumination) and then focused on the reactor. The lamps was located on the top of the solution with the distance of $50 \mathrm{~mm}$. The initial concentration of Rhodamine-B (RhB) solution was $5 \mathrm{mg} / \mathrm{L}$. $0.1 \mathrm{~g}$ of the prepared photocatalyst was added into $100 \mathrm{~mL} \mathrm{RhB}$ solution. The degradation reaction was performed at room temperature. After regular intervals, the samples were removed and centrifuged to separate the photocatalyst for analysis. The concentration of RhB was measured by a T6 spectrophotometer (Purkinje General Company, China) at $554 \mathrm{~nm}$ and analyzed by Lambert-Beer law.

\section{Results and Discussion}

\subsection{Characterization of Samples}

The XRD patterns of the prepared samples are presented in Figure 1. The diffraction patterns of all the samples match well with those of $\mathrm{ZnAl} \mathrm{LDHs}$ with $\mathrm{Zn} / \mathrm{Al}$ ratio of 2 (JCPDS file no. 48-1023). Other peaks were not found indicating pure phase synthesis of $\mathrm{ZnAl} \mathrm{LDHs.} \mathrm{The}$ intensity of diffraction peaks decreases with the increase in $\mathrm{Co}^{2+}$ content owing to the introduction of Co ions into the layers. Further ob-

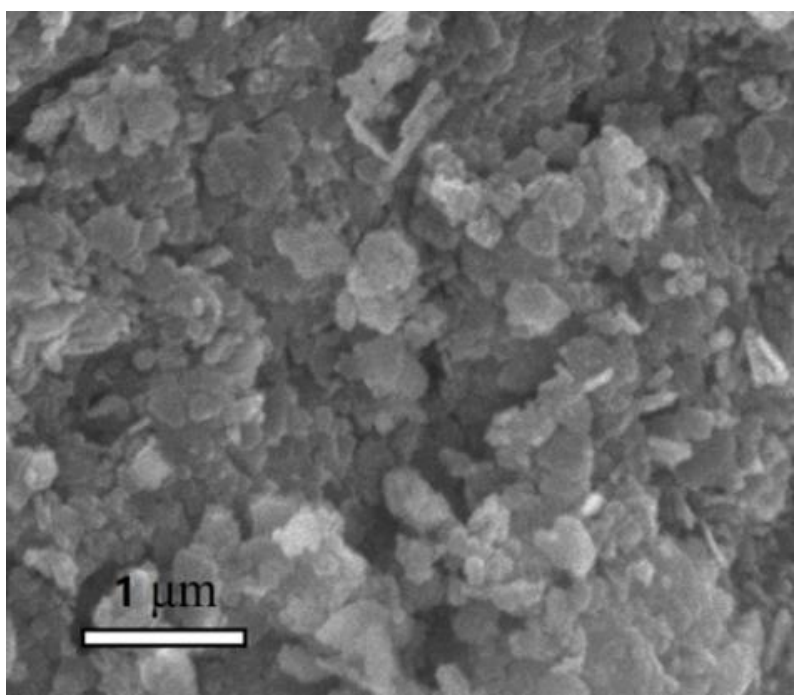

servation shows that, with the increase in $\mathrm{Co}^{2+}$ content, the peak of plane (003) moves to lower angle, while that of plane (110) moves to higher angle. Considering that the parameter $a=2$ $\times \mathrm{d}(110)$ corresponds to the cation-cation distance within the Brucite layer, and the parameter $c=3 \times \mathrm{d}(003)$ to its thickness, both parameters generally increase when $\mathrm{Co}^{2+}$ cations are inserted into the lattice of the $\mathrm{LDH}$ structure due to a partial substitution of $\mathrm{Al}^{3+}$ by $\mathrm{Co}^{2+}$. Because the ionic radius of $\mathrm{Co}^{2+}$ is bigger than that of $\mathrm{Al}^{3+}$ (ionic radius $0.065 \mathrm{~nm}$ for $\mathrm{Co}^{2+}$, and $0.054 \mathrm{~nm}$ for $\mathrm{Al}^{3+}$ ) [25], the replacement of $\mathrm{Al}^{3+}$ by $\mathrm{Co}^{2+}$ causes the increase in cation-cation distance and reduces the electrostatic interaction and increase of interlayer distance [26].

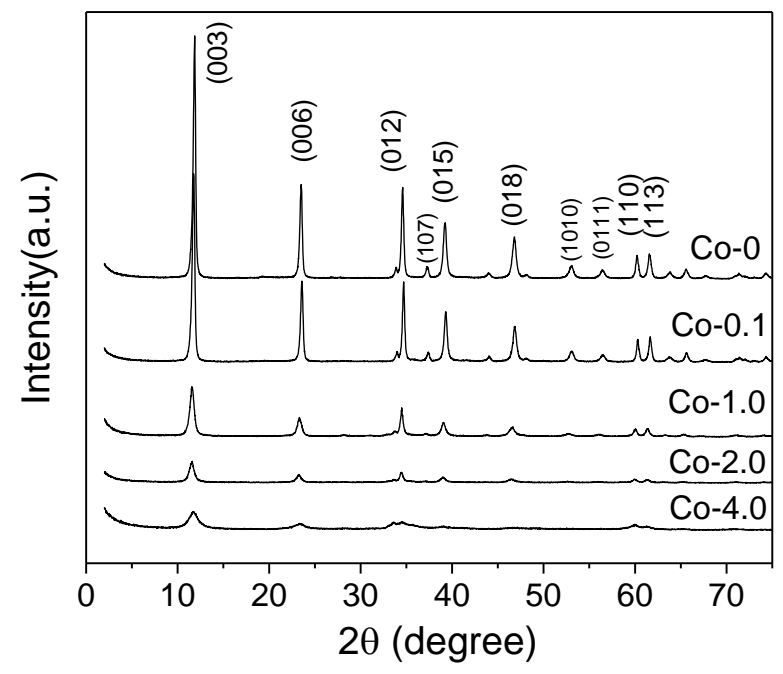

Figure 1. XRD patterns of Co-doped $\mathrm{ZnAl}$ $\mathrm{LDHs}$

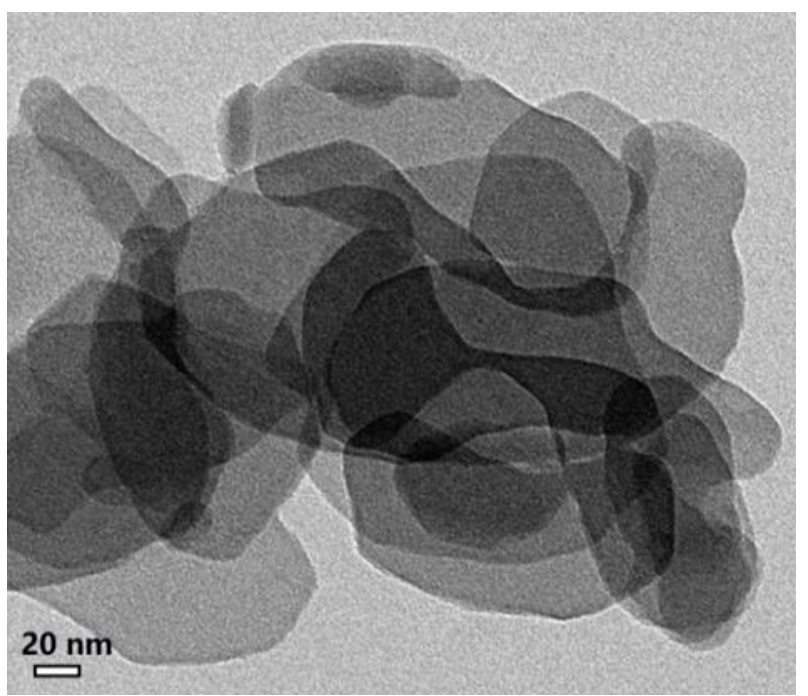

Figure 2. SEM and TEM images of Co-doped ZnAl LDH 
The morphology of selected sample Co-1.0 was observed by SEM and TEM techniques, the results are shown in Figure 2. It can be seen from SEM image that Co-doped ZnAl-LDH nanoparticles display obvious lamellar crystal with layered structure, but the material layers pile up together. TEM image shows the laminar hexagonally-shaped morphology, which is typical of LDHs.

The surface area and pore diameter distribution of samples are determined by nitrogen physical adsorption method. Figure 3(a) shows the nitrogen adsorption-desorption isotherms of ZnAl-LDHs and CoZnAl-LDHs with different Co doping contents. For all the samples, typical type IV isotherms with a distinct hysteresis loops are observed in the range of 0.2-1.0 p/po, which is characteristic of porous materials, suggesting well the presence of mesopores in the nanoplates. This is derived mainly from the platelet stacking of $\mathrm{ZnAl}-\mathrm{LDH}$ s or CoZnAlLDHs nanoparticles. The isotherm also shows adsorption at relative pressures $\left(p / p_{0}\right)$ approaching 1.0, suggesting the formation of large macropores [27]. The pore diameter distributions of all samples are shown in the insets of Figure 3(b). It can be found that all samples have intense pore distribution in mesopore $(2-10 \mathrm{~nm})$ and broad distribution in macropore $(10-80 \mathrm{~nm})$, indicating coexist of mesopore and macropore. This hierarchical structure with meso and macropores can serve as efficient transport paths for reactants and products in photocatalytic reactions. Moreover, the BET specific surface area increases with the Co doping amount increasing, except for Co-4.0. The observed specific surface areas are 22.92 , $27.98,57.24,64.57$, and $56.62 \mathrm{~m}^{2} / \mathrm{g}$ for samples

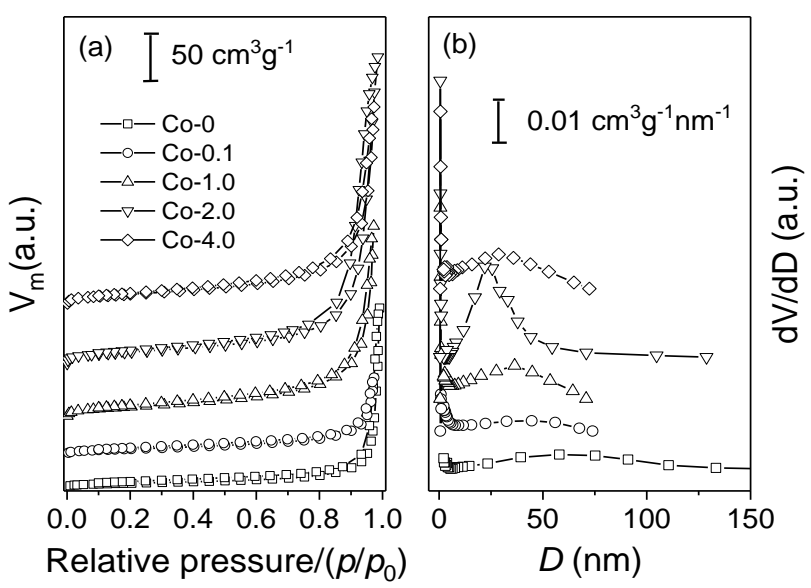

Figure 3. Adsorption-desorption isotherms (a) and pore size distribution curves (b) of Co-doped ZnAl LDHs
Co-0, Co-0.1, Co-1.0, Co-2.0 and Co-4.0, respectively.

$\mathrm{X}$-ray photoelectron spectroscopy (XPS) is used to analyze the chemical component and element valence states of the sample, the results are shown in Figure 4. The survey spectrum (Figure 3a) indicates that the sample is mainly composed of elements of $\mathrm{Zn}, \mathrm{Co}, \mathrm{Al}, \mathrm{O}$, and C. High-resolution XPS spectrum of Co-2p is shown in Figure $4 \mathrm{~b}$. The Co-2p spectra exhibited the expected spin-orbit split doublet, with Co- $2 \mathrm{p}_{3 / 2}$ and Co- $2 \mathrm{p}_{1 / 2}$ components at 780.2 and $796.1 \mathrm{eV}$ binding energy, respectively, and satellites at 784.9 and $802.1 \mathrm{eV}$ indicative of high-spin divalent $\mathrm{Co}^{2+}$ species within the CoAl-LDH layers [28]. Two binding energies at $1021.2 \mathrm{eV}$ and $1044.2 \mathrm{eV}$ correspond to $\mathrm{Zn}-2 \mathrm{p}_{3 / 2}$ and $\mathrm{Zn}-2 \mathrm{p}_{1 / 2}$, indicating the presence of $\mathrm{Zn}^{2+}$ species bonding with oxygen [21,29]. The binding energy for Al-2p at $74.2 \mathrm{eV}$ is associated to an aluminum hydroxide species $\mathrm{Al}(\mathrm{OH}) \mathrm{n}$ [20,29]. The element composition estimated from XPS was $6.09 \%, 12.66 \%$, and $5.58 \%$ for $\mathrm{Co}, \mathrm{Zn}$, and $\mathrm{Al}$, respectively, showing the $\mathrm{Co} / \mathrm{Zn} / \mathrm{Al}$ ratio was $1.1 / 2.27 / 1$. Compared with the designed $\mathrm{Co} / \mathrm{Zn} / \mathrm{Al}$ ratio of $1 / 2 / 1$, the $\mathrm{Al}$ content is slightly less, perhaps attributed to the incompletely precipitation of $\mathrm{Al}$ element during the preparation at $\mathrm{pH}$ of 10 .

Figure 5 presents the UV-vis diffuse reflectance spectra of all samples. Here $F(R)$ represents the Kubelka-Munk function (K-M), which is expressed as Equation (1), where, $R$ is reflectance and $F(R)$ is $\mathrm{K}-\mathrm{M}$ function.

$$
F(R)=\frac{(1-R)^{2}}{2 R}
$$

The UV-Vis diffuse reflectance spectrum for the $\mathrm{ZnAl} \mathrm{LDH}$ shows a weak absorption peak in the spectral region of $200-400 \mathrm{~nm}$, which is due to the electronic transition of $\mathrm{ZnAl} \mathrm{LDH}$ from the O-2p state to the metal $n$ s or $n p$ levels ( $n=4$ for $\mathrm{Zn}$ and $n=3$ for $\mathrm{Al}$ ) [20]. The low absorption ability of $\mathrm{ZnAl} \mathrm{LDH}$ indicates the low photocatalytic activity, which was also observed by other authors [30,31]. The CoZnAl $\mathrm{LDH}$ samples display two distinct absorption features, a strong absorption band in the ultraviolet light range and a broad band in the visible region centered around $500 \mathrm{~nm}$ attributable to $d-d$ transitions of octahedral $\mathrm{Co}^{2+}$ within the CoZnAl LDH layer [28,32]. It is observed that, with the Co doping amount increasing, the absorption band shifts to higher wavelength and the intensity of the absorption peak around $500 \mathrm{~nm}$ increases, indicating the increase in 
absorption for visible light.

\subsection{Photocatalytic Activities}

The catalytic activity of the as-synthesized catalysts was evaluated by the degradation of $\mathrm{RhB}$ aqueous solution under visible light irradiation. The evolution of the relative concentration of RhB aqueous solution as a function of irradiation time over different photocatalysts is shown in Figure 6. As shown in Figure 6, the adsorption percentage of $\mathrm{RhB}$ on the catalyst is about $32 \%$ (shown as blank in Figure 6), while the self-degradation of $\mathrm{RhB}$ in the absence of catalyst is about $30 \%$. The photodegradation percentage of $\mathrm{RhB}$ over bulk $\mathrm{ZnAl} \mathrm{LDH}$ (sample Co-0) reaches $48 \%$ after visible light irradiation for $180 \mathrm{~min}$. For $\mathrm{ZnAl} \mathrm{LDH,} \mathrm{the} \mathrm{ab-}$ sorption band energy is so high $(3.21 \mathrm{eV})$ that the electrons cannot be excited under the irradiation of visible light. Thus, the photodragation percentage of $\mathrm{RhB}$ over $\mathrm{ZnAl} \mathrm{LDH}$ is attributed to the strongly photosensitization of $\mathrm{RhB}$ [33]. When $\mathrm{ZnAl} \mathrm{LDH}$ is doped by $\mathrm{Co}^{2+}$, the degradation percentage over Co-doped ZnAl LDHs can reach 75-87 \% after visible light irradiation for $180 \mathrm{~min}$, indicating the

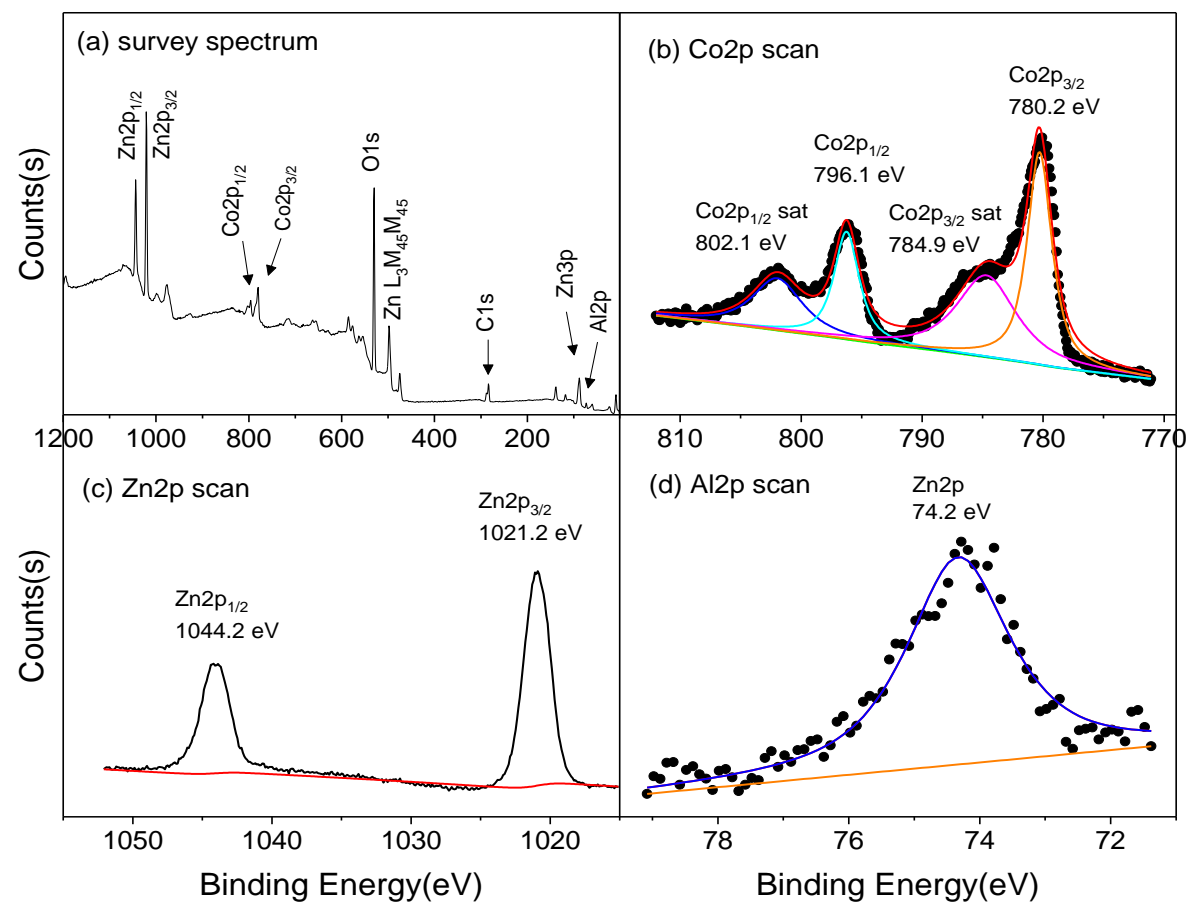

Figure 4. XPS spectra of selected sample Co-1.0: (a) survey spectrum, (b) Co-2p, (c) Zn-2p, (d) Al

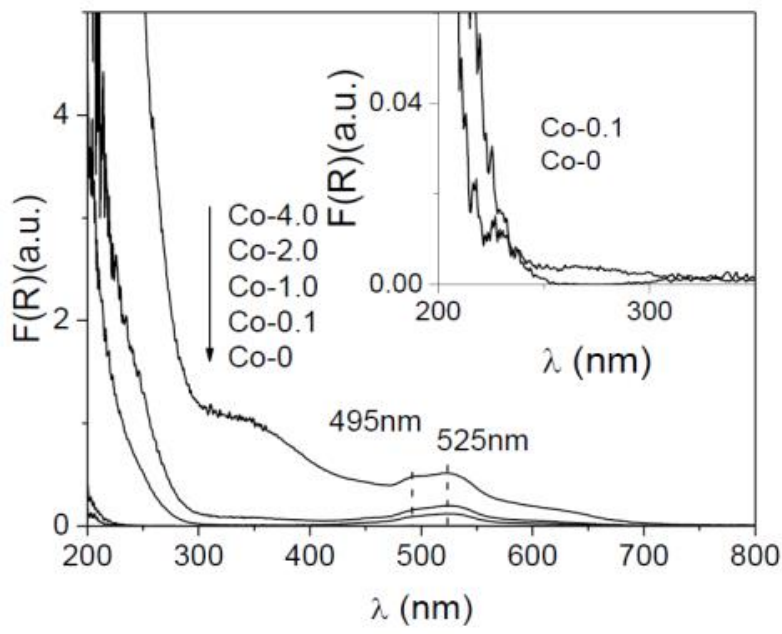

Figure 5. UV-vis diffuse reflectance spectra of Co-doped ZnAl LDHs

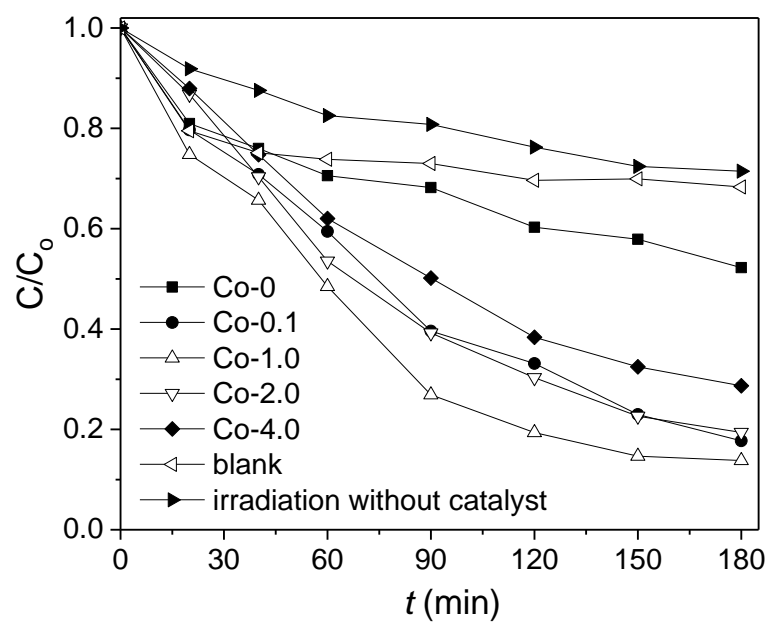

Figure 6. Degradation of RhB over different photocatalysts 
doping of Co into ZnAl LDH improve the photocatalytic activity of $\mathrm{ZnAl} \mathrm{LDH.} \mathrm{With} \mathrm{Co} \mathrm{doping}$ amount increasing, the photocatalytic activity increases to a maximum value, then diminishes at higher Co content. The photocatalytic activities were observed in the order as follows Co- 0 $<$ Co- $4.0<$ Co- $0.1 \approx$ Co- $2.0<$ Co- 1.0 with photocatalytic degradation values of $48,71,81,82$, and $87 \%$, respectively. These results suggest that an optimum in Co content.

The Langmuir-Hinshelwood model is commonly used to describe the kinetics of photocatalytic reactions of organic compounds in aqueous solutions [34]. It relates the degradation rate $r$ and the concentration of organic compound $C$, and is expressed as follows:

$$
r=-\frac{d C}{d t}=\frac{k_{r} K_{a d} C}{1+K_{a d} C}
$$

where $k_{\mathrm{r}}$ is the intrinsic rate constant and $K_{\mathrm{ad}}$ is the adsorption equilibrium constant. When the adsorption is relatively weak and the concentration of organic compounds is low, the factor $K_{\mathrm{ad}} C$ is insignificant, and the equation can be simplified to the first-order kinetics with an apparent rate constant $\left(k_{\mathrm{app}}=k_{r} K_{a d}\right)$, which gives, after integration in the interval $\left[C, C_{0}\right]$ :

$$
\ln \frac{C_{0}}{C}=k_{a p p} t
$$

Plotting of $\ln \left(C_{0} / C\right)$ versus reaction time $t$ yields a straight line, where the slope is the apparent rate constant. Figure 7 shows the lineal plot of RhB photodegradation, which adjusts well to a pseudo-first-order kinetic behavior, as most photocatalytic degradation reactions. Apparent rate constant $k_{\text {app }}$ and the linearization coefficient $r^{2}$ are summarized in Table 2. The apparent rate values obtained for the Co-doped $\mathrm{ZnAl} \mathrm{LDHs}$ are 1.86-3.11 times higher than $\mathrm{ZnAl} \mathrm{LDH.}$

\subsection{The Proposed Mechanism}

The UV-visible spectral changes during the oxidation of $\mathrm{RhB}$ in the presence of Co-doped $\mathrm{ZnAl} \mathrm{LDH}$ was spectrophotometrically monitored (Figure 8). There were two main characteristic absorption bands of $\mathrm{RhB}$ at $\mathrm{UV}$ region $(259 \mathrm{~nm})$ and visible light region $(554 \mathrm{~nm})$, respectively. The visible band absorbance at $554 \mathrm{~nm}$, which is used to monitor residual $\mathrm{RhB}$, is responsible for $\mathrm{RhB}$ coloration because of the conjugated structure of $\mathrm{C}=\mathrm{N}$ and $\mathrm{C}=\mathrm{O}$ groups. The UV absorbance at $259 \mathrm{~nm}$ corresponds to the existence of aromatic rings in $\mathrm{RhB}$ [35]. It has been reported that RhB decolorization takes place via two competitive pathways: $\mathrm{N}$-deethylation or cleavage of the chromophore structure [36]. The signal at $554 \mathrm{~nm}$ was observed diminishing very quickly within the first $1 \mathrm{~min}$ and then slowly until $60 \mathrm{~min}$, following the decolorization of the $\mathrm{RhB}$ solution. However, no band shift was observed during the spectra evolution, indicating the destruction of $\mathrm{C}=\mathrm{N}$ and $\mathrm{C}=\mathrm{O}$ groups. Moreover, the decrease in absorbance at $259 \mathrm{~nm}$ indicated the destruction of the aromatic part, suggesting that a broken conjugated structure was predominant decolorization mechanism.

To reveal the predominant reactive species in the degradation of $\mathrm{RhB}$ over CoZnAl $\mathrm{LDH}$

\begin{tabular}{|c|c|c|c|c|c|c|}
\hline \multirow{2}{*}{ Sample } & \multicolumn{2}{|c|}{ Lattice parameters } & \multirow{2}{*}{$\begin{array}{c}\text { Crystallite } \\
\text { size/nm }\end{array}$} & \multirow{2}{*}{$\mathrm{S}_{\mathrm{BET}} / \mathrm{m}^{2} \cdot \mathrm{g}^{-1}$} & \multirow{2}{*}{$\begin{array}{c}\text { BJH pore } \\
\text { volume/ } \mathrm{cm}^{3} \cdot \mathrm{g}^{-1}\end{array}$} & \multirow{2}{*}{$\begin{array}{l}\text { Average pore } \\
\text { diameter/nm }\end{array}$} \\
\hline & $a / \mathrm{nm}$ & $c / \mathrm{nm}$ & & & & \\
\hline $\mathrm{Co}-0$ & 0.3068 & 2.2653 & 25.7 & 22.92 & 0.32 & 54.32 \\
\hline Co-0.1 & 0.3072 & 2.2755 & 25.3 & 27.98 & 0.14 & 19.26 \\
\hline Co-1.0 & 0.3079 & 2.2907 & 15.7 & 57.24 & 0.34 & 23.82 \\
\hline Co-2.0 & 0.3085 & 2.3003 & 14.3 & 64.57 & 0.55 & 33.19 \\
\hline Co- 4.0 & 0.3078 & 2.2715 & 5.9 & 56.62 & 0.35 & 24.49 \\
\hline
\end{tabular}

Table 1. Structural and textural properties of CoZnAl LDHs

Table 2. Apparent constants and linearization coefficients for the pseudo-first order model for RhB photodegradation

\begin{tabular}{llllll}
\hline Sample & Co-0 & Co-0.1 & Co-1.0 & Co-2.0 & Co-4.0 \\
\hline$k$, min $^{-1}$ & 0.00398 & 0.00961 & 0.01236 & 0.00964 & 0.00739 \\
$r^{2}$ & 0.9572 & 0.9981 & 0.9878 & 0.9967 & 0.9965 \\
\hline
\end{tabular}


photocatalysts, benzoquinone and tert-butyl alcohol (TBA) were chosen as scavengers for a superoxide radical $\left(\cdot \mathrm{O}_{2}{ }^{-}\right)$and a hydroxyl radical $(\cdot \mathrm{OH})$, respectively $[13,33]$. As shown in Figure 9 , the introduction of benzoquinone into the photodegradation system led to a slight reduction in the degradation of RhB after $180 \mathrm{~min}$ irradiation. The significant reduction of $\mathrm{RhB}$ degradation was observed due to the introduction of TBA. The above results indicated that the - $\mathrm{OH}$ radical was the main active oxidizing species rather than the $\cdot \mathrm{O}_{2}{ }^{-}$radical in the photogradation process.

On the other hand, the assistance of the dye sensitization further facilitates the degradation of $\mathrm{RhB}$. It was reported that the essence of the photosensitization was to be the increasing of $\mathrm{H}_{2} \mathrm{O}_{2}$ in the reaction system [33] and then $\mathrm{H}_{2} \mathrm{O}_{2}$

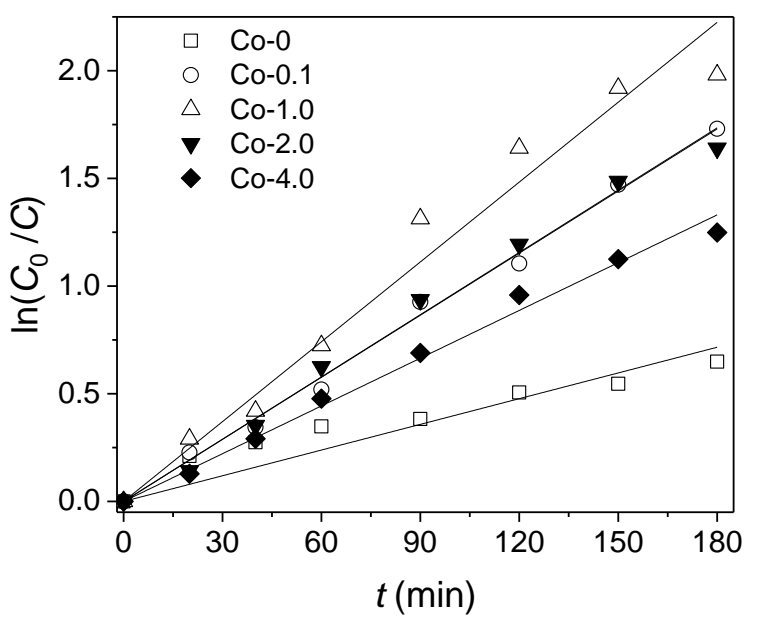

Figure 7. Fitting of RhB degradation over Codoped $\mathrm{ZnAl} \mathrm{LDHs}$

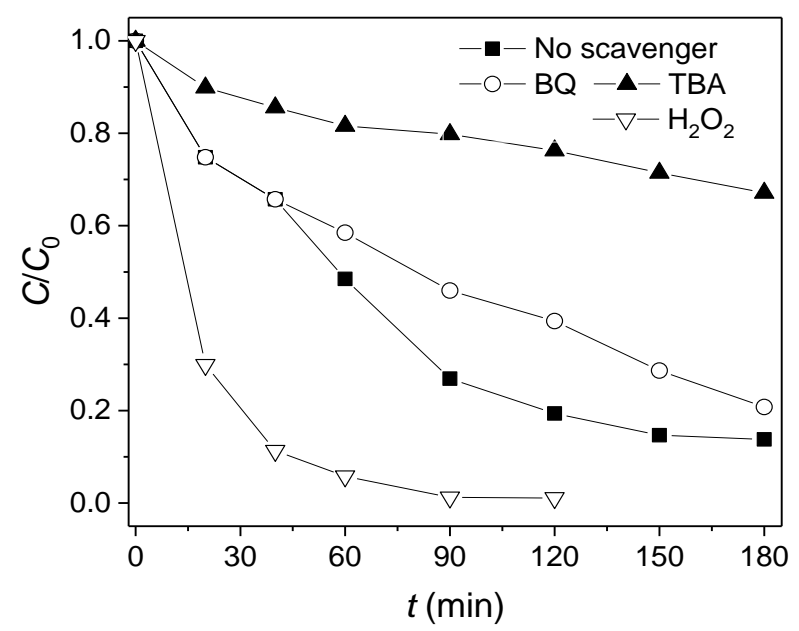

Figure 9. Photodegradation of RhB over Co-1.0 in the presence of additive reagents served as electron capture to improve the effective separation of $\mathrm{e}^{-}-\mathrm{H}^{+}$pairs, resulting in a higher photocatalytic degradation efficiency of dye [37, 38]. In this work, we also investigated the influence of $\mathrm{H}_{2} \mathrm{O}_{2}$ on the degradation of $\mathrm{RhB}$, the result is shown in Figure 9. After adding $\mathrm{H}_{2} \mathrm{O}_{2}$ into the reaction system, the $\mathrm{RhB}$ concentration declined rapidly and completely after irradiation of $90 \mathrm{~min}$. This result suggests the promotion of $\mathrm{H}_{2} \mathrm{O}_{2}$ on the $\mathrm{RhB}$ degradation.

Furthermore, the degradation percentages of $\mathrm{RhB}$ over Co-doped $\mathrm{ZnAl} \mathrm{LDH}$ s with different Co doping levels showed that an optimum in the Co content. Here it is proposed that $\mathrm{Co}^{2+}$ acts as a dopant into the $\mathrm{LDH}$ layer sheets, which can capture the photogenerated holes and electrons and suppress their recombination, increasing the life of excited charge carri-

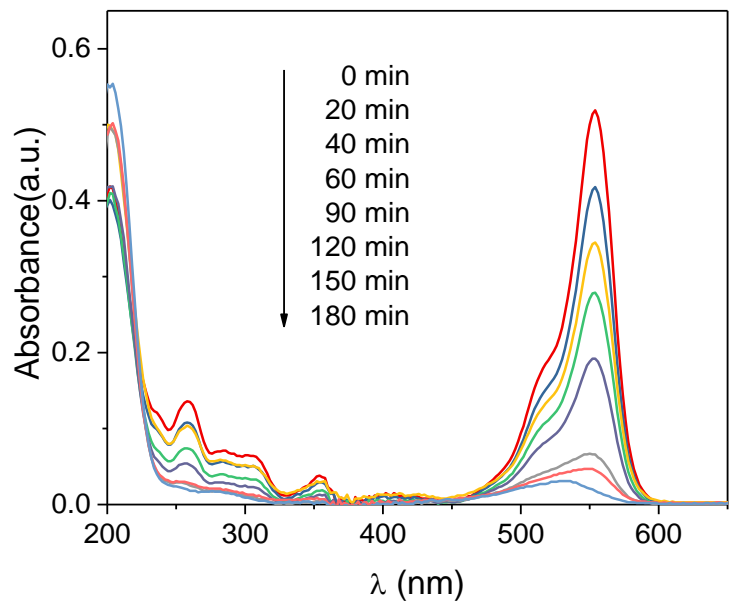

Figure 8. The UV-visible spectra of RhB solution during irradiation under visible light

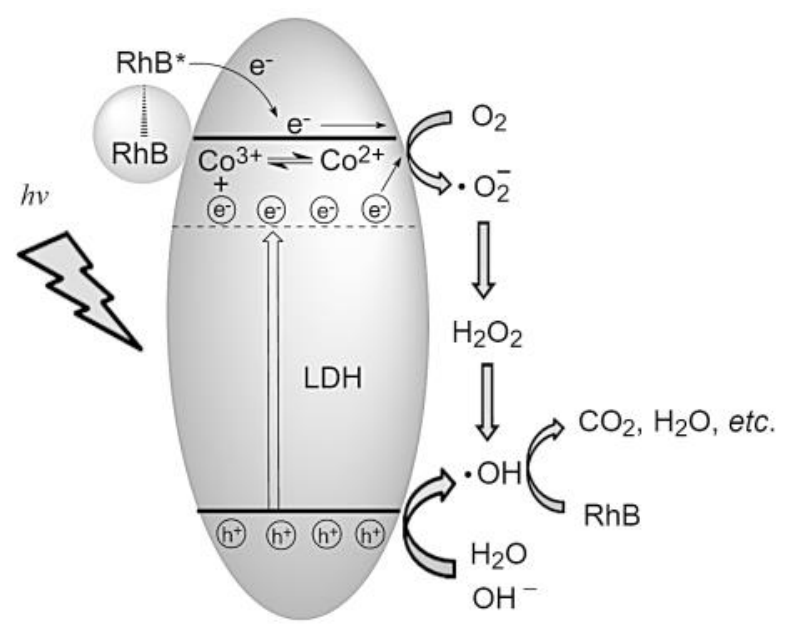

Figure 10. A proposed visible light photodegradation mechanism of $\mathrm{RhB}$ over Co-doped $\mathrm{LDH}$ 
er in the optimum amount. However, in a higher concentration, Co species do not act as trapping sites but electron-hole recombination centers [21]. Thus a higher degradation percentage of $\mathrm{RhB}$ was obtained over Co-1.0 sample in this work.

Based on the results, we propose a mechanism based on the $\cdot \mathrm{OH}$ as the main active species and $\mathrm{Co}^{2+}$ as the charge separator (Figure 10). When Co-doped $\mathrm{ZnAl} \mathrm{LDH} \mathrm{is} \mathrm{exposed} \mathrm{to}$ visible light, electrons are generated from $\mathrm{CoO}_{6}$ octahedrons in the layer sheets. The photogenerated holes move to the surface of the catalyst and react with water and $\mathrm{OH}^{-}$ions to yield - OH radicals. The electrons may react with adsorbed oxygen on the catalyst surface to produce superoxide $\left(\cdot \mathrm{O}_{2}^{-}\right)$. Superoxide $\left(\cdot \mathrm{O}_{2}^{-}\right)$can further react with adsorbed $\mathrm{H}^{+}$to produce peroxide radicals $(\cdot \mathrm{OOH})$, further yielding $\mathrm{H}_{2} \mathrm{O}_{2}$ which further generate hydroxyl radicals $(\cdot \mathrm{OH})$. Hydroxyl $(\cdot \mathrm{OH})$ is highly reactive species that will oxidize/degrade RhB into simple molecules. On the other hand, under irradiation of visible light, the photo-generated electrons reduce the $\mathrm{Co}^{3+}$ species present on the catalyst surface (electron trap), favoring the charge separation and producing an accumulation of $\mathrm{h}^{+}$which can move toward $\mathrm{OH}^{-}$adsorbed and produce $\cdot \mathrm{OH}[18,19,21]$. To recover its oxidation estate $\mathrm{Co}^{3+}$, the capture $\mathrm{e}^{-}$are transfer toward $\mathrm{H}^{+}$adsorbed on the surface and leading to the formation of $\mathrm{H}_{2}$, analogously as when is employed an organic pollutant as sacrificial molecule for the $\mathrm{H}_{2}$ evolution [18]. In addition, the absorption of the visible light over $\mathrm{RhB}$ could excites the RhB to form electrons to inject into the conduction band of Co-doped $\mathrm{ZnAl}$ $\mathrm{LDH}$, which is called dye sensitization producing $\cdot \mathrm{O}_{2}-$ or $\mathrm{H}_{2} \mathrm{O}_{2}$ can facilitate the degradation of the $\mathrm{RhB}$ molecule [33]. The proposed the mechanism involving the sequence of reactions is illustrated as follows:

$$
\begin{aligned}
& \mathrm{CoZnAl} \mathrm{LDH}+h v \rightarrow \mathrm{CoZnAl} \mathrm{LDH}\left(\mathrm{e}^{-}+\mathrm{h}^{+}\right) \\
& \mathrm{h}^{+}+\mathrm{H}_{2} \mathrm{O} \rightarrow \cdot \mathrm{OH}+\mathrm{H}^{+} \\
& \mathrm{h}^{+}+\mathrm{OH}^{-} \rightarrow \cdot \mathrm{OH} \\
& \mathrm{RhB}+h v \rightarrow \mathrm{RhB}^{*} \\
& \mathrm{RhB}^{*} \rightarrow \mathrm{e}^{-}+\mathrm{RhB}^{+} \\
& \mathrm{e}^{-}+\mathrm{O}_{2} \rightarrow \cdot \mathrm{O}_{2} 2^{-} \\
& \cdot \mathrm{O}_{2}{ }^{-}+\mathrm{H}^{+} \rightarrow \cdot \mathrm{HOO} \\
& \cdot \mathrm{HOO}^{+} \cdot \mathrm{HOO} \rightarrow \mathrm{H}_{2} \mathrm{O}_{2}+\mathrm{O}_{2} \\
& \mathrm{H}_{2} \mathrm{O}_{2}+\mathrm{H}^{+}+\mathrm{e}^{-} \rightarrow \cdot \mathrm{OH} \\
& \cdot \mathrm{OH}+\mathrm{RhB}\left(\mathrm{RhB}^{+}\right) \rightarrow \text { Degradation products }
\end{aligned}
$$

\section{Conclusions}

The high crystallinity Co-doped ZnAl LDHs based on $\mathrm{Co} / \mathrm{Zn} / \mathrm{Al}$ molar ratios ranging from 0.1:2:1 to $4: 2: 1$ were prepared by coprecipitation method. The doping of $\mathrm{Co}^{2+}$ into the $\mathrm{LDH}$ sheets increases the light absorption capacity of $\mathrm{ZnAl} \mathrm{LDH}$ materials. The formed $\mathrm{CoO}_{6}$ octahedrons contributes the excitation of electrons under visible light. The doped cobalt ions server as the photo-generated charges separator which effectively separates the excited electrons and holes, resulting in the higher $\mathrm{RhB}$ photocatalytic degradation efficiency. The process of the RhB degradation has been found to fit the first-order kinetics according to the Langmuir-Hinshelwood model. A RhB degradation mechanism based on the hydroxyl radicals was supposed. The approach which improves the visible light photocatalytic activity of LDH materials by doping transition metals into LDH sheets can be extended to prepare visible-light-driven $\mathrm{LDHs}$.

\section{Acknowledgements}

The authors are grateful for financial support from the Research Fund for the Scientific Project of Liaoning Science and Technology Department (No. 201602589).

\section{References}

[1] Xia, S., Zhang, X., Zhou, X., Meng, Y., Xue, J., $\mathrm{Ni}, \mathrm{Z}$. (2017). The Influence of Different $\mathrm{Cu}$ Species onto Multi-copper-contained Hybrid Materials' Photocatalytic Property and Mechanism of Chlorophenol Degradation. Applied Catalysis B: Environmental, 214 (Supplement C): 78-88.

[2] Evans, D.G., Slade, R.C. (2006). Structural Aspects of Layered Double Hydroxides. in: Duan, X., Evans, D.G. (eds.). Layered Double Hydroxides, pp. 1-87. Springer, Berlin, Heidelberg.

[3] Oh, J.-M., Biswick, T.T., Choy, J.-H. (2009). Layered Nanomaterials for Green Materials. Journal of Materials Chemistry, 19(17): 25532563.

[4] Rives, V. (2001). Layered Double Hydroxides: Present and Future, Nova Publishers, New York.

[5] Xu, Z.P., Zhang, J., Adebajo, M.O., Zhang, H., Zhou, C. (2011). Catalytic Applications of Layered Double Hydroxides and Derivatives. Applied Clay Science, 53(2): 139-150.

[6] Timár, Z., Varga, G., Muráth, S., Kónya, Z., Kukovecz, Á., Havasi, V., Oszkó, A., Pálinkó, I., Sipos, P. (2017). Synthesis, Characteriza- 
tion and Photocatalytic Activity of Crystalline $\mathrm{Mn}(\mathrm{II}) \mathrm{Cr}$ (III)-layered Double Hydroxide. Catalysis Today, 284(Supplement C): 195-201.

[7] Moaty, S.A.A., Farghali, A.A., Moussa, M., Khaled, R. (2017). Remediation of Waste Water by $\mathrm{Co}-\mathrm{Fe}$ Layered Double Hydroxide and Its Catalytic Activity. Journal of the Taiwan Institute of Chemical Engineers, 71 (Supplement C): 441-453.

[8] Silva, C.G., Bouizi, Y., Fornés, V., García, H. (2009). Layered Double Hydroxides as Highly Efficient Photocatalysts for Visible Light Oxygen Generation from Water. Journal of the American Chemical Society, 131(38): 1383313839 .

[9] Mantilla, A., Jácome-Acatitla, G., MoralesMendoza, G., Tzompantzi, F., Gómez, R. (2011). Photoassisted Degradation of 4Chlorophenol and p-Cresol using $\mathrm{MgAl} \mathrm{Hy}-$ drotalcites. Industrial \& Engineering Chemistry Research, 50(5): 2762-2767.

[10] Nejati, K., Davary, S., Saati, M. (2013). Study of 2,4-Dichlorophenoxyacetic Acid (2,4-D) Removal by $\mathrm{Cu}$-Fe-layered Double Hydroxide from Aqueous Solution. Applied Surface Science, 280: 67-73.

[11] Xia, S.J., Liu, F.X., Ni, Z.M., Xue, J.L., Qian, P.P. (2013). Layered Double Hydroxides as Efficient Photocatalysts for Visible-light Degradation of Rhodamine B. Journal of Colloid and Interface Science, 405: 195-200.

[12] Xia, S., Qian, M., Zhou, X., Meng, Y., Xue, J., $\mathrm{Ni}$, Z. (2017). Theoretical and Experimental Investigation into the Photocatalytic Degradation of Hexachlorobenzene by $\mathrm{ZnCr}$ Layered Double Hydroxides with Different Anions. Molecular Catalysis, 435 (Supplement C): 118-127.

[13] Lan, M., Fan, G., Yang, L., Li, F. (2014). Significantly Enhanced Visible-light-induced Photocatalytic Performance of Hybrid $\mathrm{Zn}-\mathrm{Cr}$ Layered Double Hydroxide/Graphene Nanocomposite and the Mechanism Study. Industrial \& Engineering Chemistry Research, 53(33): 12943-12952.

[14] Xu, D., Rui, Y., Li, Y., Zhang, Q., Wang, H. (2015). Zn-Co Layered Double Hydroxide Modified Hematite Photoanode for Enhanced Photoelectrochemical Water Splitting. Applied Surface Science, 358 (Part A): 436-442.

[15] Abderrazek, K., Najoua, F.S., Srasra, E. (2016). Synthesis and Characterization of [Zn-Al] LDH: Study of the Effect of Calcination on the Photocatalytic Activity. Applied Clay Science, 119 (Part 2): 229-235.

[16] Sivakumar, A., Murugesan, B., Loganathan, A., Sivakumar, P. (2014). A Review on Decol- ourisation of Dyes by Photodegradation using Various Bismuth Catalysts. Journal of the Taiwan Institute of Chemical Engineers, 45(5): 2300-2306.

[17] Zhu, J., Zhu, Z., Zhang, H., Lu, H., Qiu, Y., Zhu, L., Küppers, S. (2016). Enhanced Photocatalytic Activity of Ce-doped Zn-Al Multimetal Oxide Composites Derived from Layered Double Hydroxide Precursors. Journal of Colloid and Interface Science, 481, 144-157.

[18] Morales-Mendoza, G., Alvarez-Lemus, M., López, R., Tzompantzi, F., Adhikari, R., Lee, S.W., Torres-Martínez, L.M., Gómez, R. (2016). Combination of Mn Oxidation States Improves the Photocatalytic Degradation of Phenol with $\mathrm{ZnAl}$ LDH Materials without a Source of $\mathrm{O}_{2}$ in the Reaction System. Catalysis Today, 266: 62-71.

[19] Morales-Mendoza, G., Tzompantzi, F., García-Mendoza, C., López, R., De la Luz, V., Lee, S.-W., Kim, T.-H., Torres-Martínez, L.M., Gómez, R. (2015). Mn-doped Zn/Al Layered Double Hydroxides as Photocatalysts for the 4-Chlorophenol Photodegradation. Applied Clay Science, 118: 38-47.

[20] Mendoza-Damián, G., Tzompantzi, F., Mantilla, A., Pérez-Hernández, R., HernándezGordillo, A. (2016). Improved Photocatalytic Activity of $\mathrm{SnO}_{2}-\mathrm{ZnAl} \mathrm{LDH}$ Prepared by One Step $\mathrm{Sn}^{4+}$ Incorporation. Applied Clay Science, 121-122: 127-136.

[21] Wang, X., Wu, P., Lu, Y., Huang, Z., Zhu, N., Lin, C., Dang, Z. (2014). NiZnAl Layered Double Hydroxides as Photocatalyst under Solar Radiation for Photocatalytic Degradation of Orange G. Separation and Purification Technology, 132: 195-205.

[22] Parida, K., Satpathy, M., Mohapatra, L. (2012). Incorporation of $\mathrm{Fe}^{3+}$ into Mg/Al Layered Double Hydroxide Framework: Effects on Textural Properties and Photocatalytic Activity for $\mathrm{H}_{2}$ Generation. Journal of Materials Chemistry, 22(15): 7350-7357.

[23] Qi, M., Fan, L., Shen, Y., Zou, H., Tian, X., Liu, D., Li, S. (2018). Improved Visible-lightinduced Photocatalytic Performance of $\mathrm{ZnAl}$ Layered Double Hydroxide by Incorporation of $\mathrm{Ni}^{2+}$. Journal of Nanoscience and Nanotechnology, 18(1): 753-760.

[24] Miao, Y., Wang, X., Wang, W., Zhou, C., Feng, G., Cai, J., Zhang, R. (2017). Synthesis of Cobalt-doped $\mathrm{ZnO} / \mathrm{rGO}$ Nanoparticles with Visible-light Photocatalytic Activity through a Cobalt-induced Electrochemical Method. Journal of Energy Chemistry, 26(3): 549-555.

[25] Shannon, R.D. (1976). Revised Effective Ionic Radii and Systematic Studies of Interatomic Distances in Halides and Chalcogenides. Acta 
Crystallographica Section A: Crystal Physics, Diffraction, Theoretical and General Crystallography, 32(5): 751-767

[26] Jawad, A., Li, Y., Lu, X., Chen, Z., Liu, W., Yin, G. (2015). Controlled Leaching with Prolonged Activity for Co-LDH Supported Catalyst during Treatment of Organic Dyes using Bicarbonate Activation of Hydrogen Peroxide. Journal of Hazardous Materials, 289 (Supplement C): 165-173.

[27] Tian, G., Chen, Y., Zhou, W., Pan, K., Dong, Y., Tian, C., Fu, H. (2011). Facile Solvothermal Synthesis of Hierarchical Flower-like $\mathrm{Bi}_{2} \mathrm{MoO}_{6}$ Hollow Spheres as High Performance Visible-light Driven Photocatalysts. J. Mater. Chem., 21(3): 887-892.

[28] Kumar, S., Isaacs, M.A., Trofimovaite, R., Durndell, L., Parlett, C.M.A., Douthwaite, R.E., Coulson, B., Cockett, M.C.R., Wilson, K., Lee, A.F. (2017). P25@CoAl Layered Double Hydroxide Heterojunction Nanocomposites for $\mathrm{CO}_{2}$ Photocatalytic Reduction. Applied Catalysis B: Environmental, 209 (Supplement C): 394-404.

[29] Wang, H., Xiang, X., Li, F. (2010). Hybrid ZnAl-LDH/CNTs Nanocomposites: Noncovalent Assembly and Enhanced Photodegradation Performance. AIChE Journal, 56(3): 768778.

[30] Hadnadjev-Kostic, M., Vulic, T., MarinkovicNeducin, R., Lončarević, D., Dostanić, J., Markov, S., Jovanović, D. (2017). Photoinduced Properties of Photocatalysts: A Study on the Modified Structural, Optical and Textural Properties of $\mathrm{TiO}_{2}-\mathrm{ZnAl}$ Layered Double Hydroxide Based Materials. Journal of Cleaner Production, 164 (Supplement C): 1-18.

[31] Yuan, X., Li, W. (2017). Graphitic- $\mathrm{C}_{3} \mathrm{~N}_{4}$ modified ZnAl-layered Double Hydroxides for Enhanced Photocatalytic Removal of Organic Dye. Applied Clay Science, 138 (Supplement C): 107-113.
[32] Lu, Y., Lin, Y., Wang, D., Wang, L., Xie, T., Jiang, T. (2011). A High Performance Cobaltdoped $\mathrm{ZnO}$ Visible Light Photocatalyst and Its Photogenerated Charge Transfer Properties. Nano Research, 4(11): 1144-1152.

[33] Yu, L., Zhang, X., Li, G., Cao, Y., Shao, Y., Li, D. (2016). Highly Efficient $\mathrm{Bi}_{2} \mathrm{O}_{2} \mathrm{CO}_{3} / \mathrm{BiOCl}$ Photocatalyst Based on Heterojunction with Enhanced Dye-sensitization under Visible Light. Applied Catalysis B: Environmental, 187: 301-309.

[34] Kim, S.-H., Ngo, H.H., Shon, H.K., Vigneswaran, S. (2008). Adsorption and Photocatalysis Kinetics of Herbicide onto Titanium Oxide and Powdered Activated Carbon. Separation and Purification Technology, 58(3): 335-342.

[35] Du, J., Bao, J., Fu, X., Lu, C., Kim, S.H. (2016). Facile Preparation of S/Fe Composites as an Effective Peroxydisulfate Activator for RhB Degradation. Separation and Purification Technology, 163: 145-152.

[36] Ahmed, K.A.M., Li, B., Tan, B., Huang, K. (2013). Urchin-like Cobalt Incorporated Manganese Oxide OMS-2 Hollow Spheres: Synthesis, Characterization and Catalytic Degradation of RhB Dye. Solid State Sciences, 15: 66-72.

[37] Sun, W.-j., Li, J., Yao, G.-p., Jiang, M., Zhang, F.-x. (2011). Efficient Photodegradation of 4-Nitrophenol by using New CuPp-TiO ${ }_{2}$ Photocatalyst under Visible Light Irradiation. Catalysis Communications, 16(1): 90-93.

[38] Su, Y., Han, Z., Zhang, L., Wang, W., Duan, M., Li, X., Zheng, Y., Wang, Y., Lei, X. (2017). Surface Hydrogen Bonds Assisted Mesoporous $\mathrm{WO}_{3}$ Photocatalysts for High Selective Oxidation of Benzylalcohol to Benzylaldehyde. Applied Catalysis B: Environmental, 217 (Supplement C): 108-114. 